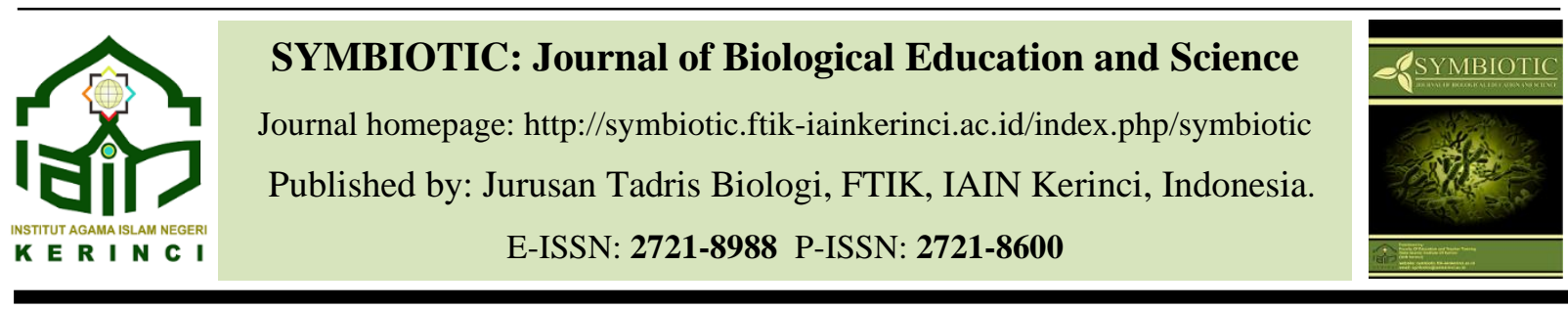

\title{
Persepsi Mahasiswa Terhadap Praktikum Biologi Umum Jurusan Tadris Biologi Fakultas Tarbiyah Dan Ilmu Keguruan IAIN Kerinci
}

\author{
Emayulia Sastria ${ }^{1}$, Prangki Alim Alfatwa ${ }^{2}$,Devie Novallyan ${ }^{3}$, Tri Susanti ${ }^{4}$ \\ ${ }^{1,2}$ IAIN Kerinci, Jl. Kapten Muradi, Kecamatan Sungai Liuk, Sungai Penuh, Jambi \\ ${ }^{3,4}$ UIN Sultan Thaha Saifuddin, Jl. Lintas Jambi - Muara Bulian KM.16, Jambi \\ e-mail korespondensi: emayuliasastria@gmail.com
}

\begin{abstract}
One way to evaluate general biology practicum is to know the students' perceptions of general biology practicum. This study aims to determine student perceptions of general biology practicum, general biology practicum planning, facilities and infrastructure of general biology practicum, and also to determine the perceptions of students towards the implementation of general biology practicum majoring in biology IAIN Kerinci. This research belongs to the category of qualitative research. To get the data the researcher used the study (1) Observation, observed the general Biology practicum, (2) Interview, semester 1 student lecturer and department head, (3) Documents, data about vision and mission department, and general Biology practicum guide. The results obtained based on the results of data analysis and discussion can be concluded (1) Perception of the General Biology practicum planning Department of Biology Tadris IAIN Kerinci is quite good. (2) Perception of the first semester biology student of IAIN Kerinci regarding the facilities and infrastructure of general biology practicum namely practicum guide is still incomplete and inadequate. (3) The first semester biology student IAIN Kerinci's perceptions regarding the implementation of general boiology practicum, firstly in each practicum the teaching assistant is still not right to use the strategy properly. Second, the media displayed is good, and also for the practicum schedule it has been said on schedule.
\end{abstract}

Keyword : Perception, General Biology, Practice

\begin{abstract}
ABSTRAK
Salah satu cara yang dilakukan untuk mengevaluasi praktikum biologi umum adalah dengan mengetahui persepsi mahasiswa terhadap praktikum biologi umum. Penelitian ini bertujuan untuk mengetahui persepsi mahasiswa terhadap praktikum biologi umum, perencanaan praktikum biologi umum, sarana dan prasarana praktikum biologi umum, dan juga untuk mengetahui persepsi mahasiswa terhadap pelaksanaan praktikum biologi umum jurusan tadris biologi IAIN Kerinci. Penelitian ini adalah penelitian kualitatif. Untuk mendapatkan data peneliti menggunakan studi (1) Observasi, mengamati pelaksanaan praktikum Biologi umum, (2) Wawancara, Mahasiswa semester 1 dosen pengampu dan ketua jurusan, (3) Dokumen, data tentang visi dan misi jurusan, dan penuntun praktikum Biologi umum. Hasil yang didapat berdasarkan hasil analisa data dan pembahasan maka dapat disimpulkan (1) Persepsi terhadap perencanaan praktikum Biologi Umum Jurusan Tadris Biologi IAIN Kerinci cukup baik. (2) Presepsi mahasiswa biologi semester 1 IAIN Kerinci mengenai sarana dan prasarana praktikum biologi umum yaitu panduan praktikum masih belum lengkap dan belum memadai. (3) Persepsi mahasiswa biologi semester 1 IAIN Kerinci mengenai pelaksanaan praktikum boiologi umum, pertama pada setiap pelaksanaan praktikum asisten dosen masih belum tepat menggunakann strategi dengan baik. Kedua, media yang ditampilkan sudah bagus, dan juga untuk jadwal praktikum sudah dikatakan sesuai jadwal.
\end{abstract}

Kata Kunci : Persepsi, Biologi Umum, Praktikum 


\section{PENDAHULUAN}

Pendidikan Tinggi adalah jenjang pendidikan setelah pendidikan menengah yang mencakup program diploma, program sarjana, program magister, program doktor, dan program profesi, serta program spesialis, yang diselenggarakan oleh perguruan tinggi berdasarkan kebudayaan bangsa Indonesia (UU, 2012). Komponen penting dalam mewujudkan tujuan pendidikan nasional salahsatunya melalui lembaga pendidikan tinggi. Institut Agama Islam Negeri (IAIN) Kerinci salah satu penyelenggara pendidikan tinggi diharapkan dapat menghasilkan tenaga kependidikan akademik dan profesional yang mengikuti kemajuan ilmu pengetahuan dan teknologi.

Adapun kemajuan pendidikan tersebut ditentukan oleh banyak faktor pendukung, salah satunya yaitu kemampuan yang dimiliki calon pendidik, dalam hal ini mahasiswa adalah praktikan yang melaksanakan program praktikum. Kemampuan mengajar harus dikuasai oleh calon pendidik sebagai bekal mengajar di satuan pendidikan sekolah kelak pada saat dia menjadi pendidik. Salah satunya guru biologi dituntut untuk memiliki keterampilan sesuai dengan bidang ilmunya, karena di dalam ilmu biologi mahasiswa tidak dituntut untuk bisa menguasai aspek kognitif dan keterampilan atau psikomotorik (Hidayah, 2018; Ferry, 2019).

Biologi merupakan salah satu mata kuliah pada jurusan tadris biologi yang memiliki banyak cabang ilmu salah satunya mata kuliah cabang dari bidang ilmu biologi yaitu biologi umum. Pada jurusan tadris biologi di IAIN Kerinci biologi umum mempelajari segala hal yang berhubungan dengan makhluk hidup dan kehidupan. Secara umum pada mata kuliah biologi umum terdiri dari 3 SKS, 2 SKS untuk teori dan 1 SKS untuk kegiatan praktikum. Pembelajaran tidak hanya dilakukan dikelas namun juga di laboratorium. Konsep awal dalam memahami pembelajaran ini dapat dipandang dari apa itu "Belajar" (Daryanto \& Rahardjo, 2012). Tujuan pembelajaran adalah terwujudnya efektivitas kegiatan belajar yang dilakukan.

Praktikum adalah sebuah pembelajaran yang dilakukan di laboratorium dimana mahasiswa diharapkan dapat menerapkan ilmu yang telah diperolehnya dalam perkuliahan khususnya biologi umum (Rustaman, 2010). Pada proses kegiatan praktikum biologi umum bertujuan agar mahasiswa mampu mengenal alat-alat laboratorium dengan baik, agar mahasiswa bisa langsung melakukan praktek secara langsung mengenai praktikum biologi umum, dan mampu menambah wawasan pengetahuan mahasiswa tentang praktikum biologi umum.

Berdasarkan observasi penulis menemukan beberapa masalah yang terdapat pada mahasiswa yang sedang melakukan praktikum biologi umum. Dalam pelaksanaan praktikum mahasiswa belum maksimal untuk mengikuti praktikum dikarenakan pada waktu SMA ada sebagian mahasiswa belum melaksanakan praktikum dengan baik, tidak hanya itu mahasiswa yang ada di semester 1 tidak semuanya berasal dari SMA atau jurusan IPA, ada beberapa mahasiswa yang berasal dari jurusan IPS bahkan ada mahasiswa yang berasal dari SMK. Dan juga mahasiswa semester 1 pada saat pertama melaksanakan praktikum tidak dijelaskan terlebih dahulu tentang pengertian dari praktikum itu sendiri. 
Tentunya pemahaman mahasiswa tentang praktikum biologi umum ini masih kurang bahkan tidak ada pengetahuan sama sekali tentang praktikum. Oleh karena itu perlu dilakukan suatu penilaian atau pandangan dari mahasiswa terhadap praktikum biologi umum di IAIN Kerinci.

Dari penelitian sebelumnya yang dilakukan oleh Endang Setya Ningsih, Rio Taufiq Nugroho, Dwi Prasetyo (2013). Tentang "persepsi mahasiswa terhadap pelaksanaan praktikum anatomi hewan pendidikan biologi FKIP UMS tahun akademik 2013/2014" Berdasarkan persepsi mahasiswa dosen pengampu praktikum anatomi hewan dan asisten sudah konsisten komunikasinya hal ini di tunjukkan dengan adanya jumlah jawaban yang rata-rata lebih dari 50\%. Hal ini selaras dengan hasil penelitian Munawaroh (2009) yang menyimpulkan bahwa mahasiswa merupakan konsumen, konsumen selalu mencari kepuasan yang maksimal untuk menikmati barang atau jasa yang mereka peroleh. Agar mahasiswa mampu memperoleh titik kepuasan saat proses belajar pembelajaran berlangsung, cara yang dapat digunakan oleh seorang pengajar atau dosen antara lain melalui penguatan dan pengelolaan karakter yang dimiliki. Dari hasil penelitian sebelumnya diatas bahwa peneliti sama-sama melihat persepsi mahasiswa terhadap praktikum, hanya saja terdapat perbedaan di mata kuliah saja. Penelitian ini bertujuan untuk mengetahui bagaimana persepsi mahasiswa terhadap proses praktikum pada mata kuliah biologi umum.

\section{METODE}

Jenis penelitian ini adalah penelitian kualitatif yang memanfaatkan paradigma penelitian interpreatif dengan tujuan membangun makna berdasarkan data-data lapangan. Teknik pengumpul data (1). Pengamatan (observasi). Pengamatan ditujukan untuk mengumpulkan data tentang persepsi mahasiswa semester 1 terhadap praktikum mata kuliah biologi umum di IAIN Kerinci. (2) Wawancara (Interview). Wawancara yang peneliti lakukan adalah wawancara yang terstruktur yaitu wawancara yang dilakukan dengan menggunakan pedoman wawancara secara sistematis dan lengkap untuk pengumpulan data. (3) Dokumentasi, berupa data tentang visi dan misi jurusan, dan penuntun praktikum Biologi umum.

Analisa data adalah proses mengatur urutan data, mengorganisasikannya ke dalam suatu pola, kategori dan satuan uraian dasar (Afifudin dan Beni Saebani, 2012). Teknik analisis data yang penulis gunakan untuk mendeskripsikan data dan menarik kesimpulan dalam penelitian, yaitu metode deduktif. Untuk menganalisis data yang diperoleh, penyusun menggunakan analisis deskriptif yang dikembangkan oleh Milles dan Hubberman dengan tiga langkah sebagai berikut: (1) Reduksi data : kegiatan pemilihan, penyederhanaan dan transformasi data kasar yang muncul dari catatan tertulis dilapangan, sehingga menjadi lebih fokus sesuai dengan objek penelitian. Reduksi data berlangsung selama proses penelitian sampai tersusunya laporan akhir penelitian. (2) Penyajian data : Penyajian data sekumpulan informasi yang memberikan kemungkinan adanya penarikan kesimpulan dan pengambilan tindakan. (3) Penarikan kesimpulan: merupakan suatu kegiatan konfigurasi yang utuh. 
Setelah analisis dilakukan, maka penulis dapat menyimpulkan masalah yang telah ditetapkan oleh penulis (Sugiyono 2013).

Teknik keabsahan data menggunakan triangulasi. Triangulasi teknik meliputi observasi, wawancara, dan dokumentasi. Triangulasi ini selain digunakan untuk mengecek kebenaran data juga dilakukan untuk memperkaya data. Sedangkan triangulasi sumber, yaitu membandingkan dan mengecek balik derajat kepercayaan suatu informasi yang diperoleh melalui waktu dan alat yang berbeda. Setelah peneliti melakukan observasi, kemudian mengadakan wawancara pada beberapa mahasiswa, dosen dan asisten untuk mendalami dan mengetahui kredibilitas data yang di peroleh melalui wawancara, serta mengambil gambar (foto) atau catatan kecil sebagai dokumentasi (Moleong, 2004).

\section{HASIL DAN PEMBAHASAN}

\section{Persepsi Mahasiswa Terhadap Perencanaan Praktikum Biologi Umum Jurusan Tadris Biologi IAIN Kerinci}

Perencanaan sebelum melakukan praktikum sangat mempengaruhi hasil yang diinginkan dalam praktikum itu sendiri. Perencanaan adalah sebuah proses pertama ketika hendak melakukan pekerjaan baik dalam bentuk pemikiran maupun kerangka kerja agar tujuan yang hendak dicapai mendapatkan hasil yang optimal (Indrawan, 2015; Ferry, 2019). Perencanaan itu sendiri merupakan bagian dari sistem manajemen. Menurut Terry (2000) "management is a distinct process consisting of planning, organizing, actuating, and controlling, performed to determine and accomplish stated objectives by the use of human beings and other resources". Sedagkan menurut Mulyono (2009) menyatakan "manajemen adalah sebuah proses yang khas yang terdiri dari perencanaan, pengorganisasian, penggerakan dan pengawasan serta evaluasi yang dilakukan pihak pengelola organisasi untuk mencapai tujuan bersama dengan memberdayakan sumber daya lainnya. Manajemen yang baik akan menghasilkan produk yang baik pula.

Berdasarkan wawancara peneliti dengan beberapa mahasiswa didapatkan:

\footnotetext{
"Menurut pandangan saya bahwa perencanaan praktikum yang dimulai dari komunikasi dosen dengan asisten dosen biologi pada praktikum biologi umum kurang terjalin dengan baik. Untuk persamaan persepsi antar asisten sudah cukup baik dalam pelaksanaan praktikum, dalam segi penataan kelompok yang dibagikan oleh asisten dosen sudah merata berdasarkan tingkat kemampuan. Dalam pengorganisasian alat dan bahan praktikum sudah terstruktur dengan baik serta dalam pembagian alat praktikum tiap kelompok sudah dibagikan secara merata sehingga kami selaku praktikan tinggal menggunakannya saja,karena alat-alat labor sudah diletakkan di atas meja. dan untuk informasi yang disampaikan ke praktikan sudah baik dan benar" (Informan 1).
} 
Seharusnya sebelum praktikum dimulai diadakan responsi sebagai pengantar praktikum dengan menjelaskan tujuan, alat bahan, cara kerja dan teori yang mendukung (Saputro Budiono, 2016). Persiapan sebelum praktikum bukan hanya dilakukan oleh dosen dan asisten., namun juga mahasiswa yang akan praktikum. Menurut (Jayaningrat,dkk: 2017): Kesiapan belajar merupakan hal yang mendasar yang harus ada dalam diri seorang untuk mengikuti pembelajaran. Seseorang yang memiliki kesiapan belajar yang baik tentunya akan siap mengikuti pembelajaran dan akan memperoleh hasil belajar yang memuaskan.

Hal yang sama juga dikomentari oleh mahasiswa biologi yang lainnya seperti di bawah ini :

"Pandangan saya mengenai perencanaan praktikum saya menilai bahwa komunikasi dosen dengan asisten dosen dapat dikatakan kurang baik, untuk persamaan persepsi antar asisten sudah baik. Dalam pembagian kelompok sudah cukup baik dan benar disertai penataan kelompok sudah dikatakan teratur. Mengenai alat dan bahan laboratorium memang sudah terstruktur dengan baik sesuai dengan letaknya masing-masing pembagian alat praktikum memang sudah memang merata untuk semua kelompok dan tidak ada kelompok yang tidak kebagian. Untuk informasi yang disampaikan asisten dosen ke praktikan sudah baik dan benar" (Informan 2).

Meskipun perencanaan praktikum di pandang kurang baik dari segi komunikasi dosen dengan asisten dosen yang berdasarkan hasil wawancara tersebut di atas dan tidak menutup kemungkinan dari segi yang lain hal, itu dilihat dari aspek komunikasi dosen dan asisten dosen belum terjalin dengan baik pada saat sebelum praktikum dan waktu praktikum berlangsung. seperti persamaan persepsi antar asisten penataan kelompok pengorganisasian alat dan bahan praktikum serta ketetapan penyampaian informasi ke praktikan rata-rata nya sudah terlaksana dengan baik, namun ada juga mahasiswa yang memiliki persepsi berbeda terbalik dengan hasil wawancara tersebut di atas. Hal ini terbukti dari hasil wawancara dengan salah satu mahasiswa biologi di IAIN Kerinci sebagai berikut:

\begin{abstract}
"Menurut saya perancanaan praktikum dari segi komunikasi dosen dengan asisten dosen pada saat praktikum tidak interaktif dengan baik, karena saya pernah melihat kerja sama antara dosen dan asisten begitu tidak interaktif. Untuk persamaan persepsi antar asisten menurut saya sudah sesuai, penataan kelompok dan pembagian kelompok tidak heterogen. Dalam pengorganisasian alat dan bahan praktikum tidak terstruktur dengan baik dan pembagian alat tiap kelompok sudah merata dan tinggal kami menggunakannya saja. Serta informasi yang disampaikan sudah tersampaikan dengan baik” (Informan 3).
\end{abstract}

Setelah melihat hasil wawancara penulis dengan beberapa mahasiswa biologi semester 1 IAIN Kerinci mengenai persepsi terhadap perencanaan bahwa pertama, mengenai komunikasi antara dosen dan asisten masih kurang baik dikarenakan yaitu kurangnya asistensi antara asisten dan dosen pada saat sebelum pelaksanaan pratikum dan asisten masih enggan dalam bertanya pada dosen pengampu praktikum sehingga komunikasi tidak terjalin. Oleh sebab itu perlu pemilihan asisten dengan cara pengambilan keputusan yang tepat. Persoalan pengambilan keputusan, pada dasarnya adalah bentuk pemilihan dari berbagai alternatif tindakan yang mungkin didipilih yang prosesnya melalui mekanisme tertentu dengan harapan akan menghasilkan sebuah keputusan yang terbaik (Satria Bayu, 2011). 
Dengan cara pemilihan asisten yang tepat akan mengahasilkan asisten dosen yang cepat tanggap, sehingga asistensi yang minimum bisa teratasi. Dalam pemilihan asisten juga perlu diperhatikan Nilai Kemampuan Potensi Akademik, Hasil Wawancara, Nilai Praktikum, Rekomendasi dan nilai Semester sebelumnya.

Kedua untuk persamaan persepsi antar asisten sudah dikatakan baik. Ketiga, dalam pembagian kelompok sudah baik dan merata. Keempat, mengenai alat dan bahan laboratorium sudah terstruktur dengan baik sesuai dengan letaknya masing-masing, karena Laboratorium merupakan perangkat akademis yang merupakan salah satu fasilitas di dunia pendidikan dan memiliki fungsi sebagai tempat untuk melakukan pelatihan ilmiah dan tempat untuk mengembangkan keterampilan intelektual mahasiswa (Gafur, dkk, 2013). Kelima, komunikasi antara asisten dan praktikan pada saat praktikum berlangsung sudah tersampaikan dengan baik. Khususnya jurusan Biologi yang praktikum di laboratorium sangat memerlukan pendampingan yang optimal, sedangkan peran satu dosen dirasa sangat kurang untuk memberikan pendampingan untuk 30 mahasiswa. Oleh karena itu dibutuhkan tambahan asisten dosen dalam memberikan pendampingan kepada mahasiswa.

\section{Persepsi Mahasiswa Terhadap Sarana dan Prasarana Praktikum Biologi Umum Jurusan Tadris Biologi IAIN Kerinci}

Sarana dan prasarana sangat dibutuhkan sekali didalam dunia pendidikan, guna menunjang proses pembelajaran serta membantu dalam menyampaikan tujuan pembelajaran. Sarana adalah peralatan dan perlengkapan yang secara langsung digunakan dan menunjang proses pendidikan, khususnya proses belajar mengajar seperti gedung, ruang kelas, meja, kursi, serta alat-alat dan media pengajaran. Adapun prasarana adalah fasilitas yang secara tidak langsung menunjang jalannya proses pendidikan atau pengajaran (Ibrahim Bafadal, 2003). Pengelolaan sarana dan prasarana sangat penting karena dengan adanya pengelolaan sarana dan prasarana lembaga pendidikan akan terpelihara dan jelas kegunaanya (Megasari Rika, 2014).

Mengenai sarana dan prasarana yang dibicarakan di atas, bahwa didalam ilmu biologi sangat erat sekali hubungannya dengan alat-alat dan media pembelajaran, seperti alat-alat labor biologi untuk membantu praktikan atau mahasiswa biologi dalam praktikum. Untuk mengetahui seberapa lengkap dan manfaat dari sarana dan prasarana di labor biologi IAIN Kerinci peneliti juga melaksanakan wawancara dengan informan yaitu mahasiswa atau praktikan dari semester satu yang sesuai dengan mata kuliah yang saya teliti. Adapun hasil wawancara didapatkan persepsi tentang sarana dan prasarana sebagai berikut :

"Menurut saya, mengenai sarana dan prasarana praktikum belum lengkap dan belum memadai, dan alat-alat labor saja ada yang rusak seperti mikroskop dan alat-alat 
mikroskop lainnya dan tidak bisa digunakan saat praktikum, sehingga mahasiswa mengalami kesulitan dalam pengamatan. Untuk bahan praktikum masih belum lengkap dan untuk ruangan praktikum sudah memadai dari jumlah praktikan dalam melaksanakan praktikum" (Informan 4).

Kesulitan belajar biologi disebabkan oleh beberapa faktor diantaranya yaitu siswa tidak pernah diberi pengalaman konkrit dalam mengalami suatu obyek baik melalui pengamatan di laboratorium maupun melalui lingkungan, sehingga siswa menganggap materi pelajaran biologi adalah materi abstrak dan sukar dipahami (Siti,2010). Namun ada juga mahasiswa yang memiliki persepsi berbeda terbalik dengan hasil wawancara tersebut di atas. Hal ini terbukti dari hasil wawancara dengan salah satu mahasiswa biologi di IAIN Kerinci sebagai berikut :

"Pendapat saya, sarana dan prasarana praktikum untuk saat ini masih belum lengkap dan belum memadai dari segi alat dan bahan. untuk alat labor biologi menurut saya belum begitu lengkap dan sebagian bahan bahan praktikum pada saat praktek masih kurang lengkap. Mengenai ruangan praktikum menurut saya luas rungan labor masih belum memadai dan masih sedikit sempit karena pada saat kami praktikum saya merasakan sedikit berdesak-desakan dalam ruangan praktikum" (Informan 5).

Dari hasil wawancara diatas dengan beberapa mahasiswa biologi semester 1 IAIN Kerinci mengenai sarana dan prasarana praktikum biologi umum dapat disimpulkan yaitu pertama, untuk alat-alat praktikum masih belum lengkap dan belum memadai dari jumlah praktikan. Kedua, bahan-bahan praktikum yang dibawa oleh praktikan masih belum lengkap untuk kebutuhan pada saat praktikum. Ketiga, ruangan laboratorium masih kurang luas sehingga praktikkan merasa sedikit berdesak-desakan dalam laboratorium pada saat praktikum. Walaupun sejatinya Laboratorium dalam proses pembelajaran digunakan untuk mencapai berbagai tujuan. Salah satunya tujuan kognitif yang berhubungan dengan belajar konsep-konsep ilmiah, proses pengembangan keterampilan, dan meningkatkan pemahaman tentang metode ilmiah (Mastika, 2014). Jadi, Persepsi mahasiswa terhadap sarana dan prasarana praktikum biologi umum masih dikatakan kurang baik karena masih banyak terdapat kekurangan dari sarana dan prasarana dalam praktikum dan juga ruangan laboratorium masih kurang luas dalam praktikum biologi umum.

Dukungan partisipasi dari pihak terkait sangat diperlukan agar praktikum bisa berjalan. Seperti dengan adanya bantuan sarana prasarana dan operasional pada pelaksanaan praktikum. Jika dilihat dari kondisi laboratorium, wujud dukungan dan partisipasi dari pihak Institut Agama Islam Negeri Kerinci masih kurang (Sastria,dkk 2018). Oleh sebab itu, praktikum yang dilaksanakan belum sesuai dengan kurikulum yang diinginkan diperguruan tinggi. 


\section{Persepsi Mahasiswa Terhadap Pelaksanaan Praktikum Biologi Umum Jurusan Tadris Biologi IAIN Kerinci}

Praktikum sangat penting dilaksanakan agar dapat memberikan pengalaman belajar secara nyata kepada mahasiswa. Biologi umum yang memiliki bobot 3 sks tidak cukup hanya dengan teori di kelas namun diperlukan praktek di laboratorium. Menurut (Dewi, dkk, 2014) menyatakan: Kegiatan laboratorium atau praktikum adalah bagian dari pembelajaran yang bertujuan untuk menguji dan melaksanakan suatu teori dalam keadaan nyata. Mengingat biologi umum adalah matakuliah yang membutuhkan praktek. Namun dalam pelaksanaannya tentu terdapat berbagai persepsi dari mahasiswa atau praktikan baik itu persepsi yang positif maupun yang negatif selama pelaksanaan praktikum.

Beberapa hasil wawancara dengan mahasiswa mengenai pelaksanaan praktikum biologi umum sebagai berikut :

"Kalau menurut pandangan saya asisten selalu membuka praktikum dengan salam dan memberikan sedikit pengantar tentang materi yang di praktikumkan, dan juga asisten selalu memberikan kuis di awal praktikum maupun di akhir praktikum. pelaksanaan praktikum dengan strategi yang digunakan oleh asisten dosen sudah dikatakan baik karena apa yang di jelaskan dan di praktekkan tujuannya sudah sampai pada saya sehingga saya semakin paham. Akan tetapi alangkah baiknya asisten mencari strategi lain yang lebih baik karena ada sebagian dari mahasiswa ada yang belum mengerti sepenuhnya. Untuk masalah media praktikum sudah di tampilkan sebagai tambahan dalam menunjang praktikum. Untuk waktu dan pelaksanaan yang ditetapkan tidak cukup karena terkadang waktu sedang melakukan praktikum tergesa-gesa dalam penyelesaiannya sehingga praktikum tidak efektif. Namu, pelaksanaan praktikum sudah sesuai dengan jadwal yang di tetapkan"(Informan 6).

Waktu yang tidak cukup membuat mahasiswa kurang paham dan motivasi menjadi berkurang. Untuk menambah pemahaman dan minat mahasiswa perlu adanya motivasi dari dosen pengampu dan asisten. Menurut pendapat Hasruddin dan Rezeqi (2012), dalam proses belajar mengajar, perhatian mahasiswa terhadap materi yang diberikanakan sangat mempengaruhi berhasi ltidaknya proses belajar mengajar tersebut.

Mahasiswa lain mengomentari hal yang sama mengenai pelaksanaan praktikum yaitu :

"Selama saya praktikum asisten selalu membuka praktikum seperti menyapa dan menanyakan kabar kami. Dan juga asisten selalu memberikan kuis ada yang di awal praktikum ada yang di akhir praktikum. saya menilai bahwa dalam pelaksanaan praktikum asisten dosen telah menggunakan strategi namun, strategi yang digunakan masih kurang baik untuk menyampaikan materi pada saat praktikum sehingga kami sebagai praktikan rata-rata masih mendapatkan nilai yang belum memuaskan. Untuk masalah media yang di tampilkan sudah bagus guna menambah penjelasan dari teori yang di praktekkan. Masalah waktu pelaksanaan praktikum menurut saya masih belum cukup untuk menyelesaikan praktikum karena waktu yang ada banyak dihabiskan untuk kuis, namun jadwal pelaksanaan praktikum sudah sesuai dengan jadwal yang ditentukan. kadang-kadang mahasiswa juga membantu asisten dalam menyiapkan alat dan bahan untuk praktikum" (Informan 7).

Sesuai dengan pendapat (Indriastuti, Herlina, dan Widiyaningrum, 2013)"Mahasiswa yang membantu menyiapkan alat dan bahan praktikum yang dibutuhkan untuk kegiatan praktikum sehingga secara keseluruhan tingkat pengelolaan penyelenggaraan praktikum biologi sangat baik”. Berdasarkan 
hasil wawancara dengan beberapa mahasiswa biologi semester 1 IAIN Kerinci tentang persepsi pelaksanaan praktikum biologi umum dapat disimpulkan bahwa pada setiap pelaksanaan praktikum, asisten dosen selalu membuka praktikum dengan salam dan sedikit menjelaskan materi yang di praktikumkan dan asisten selalu memberikan kuis. Asisten dosen masih belum tepat menggunakann strategi dengan baik sehingga ada sebagian dari mahasiswa yang belum mengerti yang dijelaskan oleh asisten. Media yang ditampilkan sudah baik dalam menyampaikan tujuan dari praktikum biologi umum. Dengan bantuan media yang digunakan dalam praktikum mahasiswa menjadi tidak bosan dan materi praktikum bisa dilakukan sesuai prosedur praktikum. Selain itu pada beberapa kegiatan praktikum alokasi waktu yang disediakan kurang, karena banyaknya kegiatan dan pengamatan yang membutuhkan waktu yang lama. untuk jadwal praktikum sudah dikatakan sesuai jadwal yang ditentukan oleh dosen dan asisten dosen di labor biologi IAIN Kerinci. Kesesuaian jadwal tersebut dapat dilihat dari tidak ada terjadi tumburan jadwal antara perkuliahan mahasiswa dan praktikum sehingga semua jadwal praktikum yang ditentukan dapat terlaksana.

Pada dasarnya praktik atau praktikum merupakan salah satu bentuk kegiatan belajar mengajar yang dimaksudkan untuk memantapkan penguasaan materi yang bersifat aplikatif. Melalui kegiatan yang mandiri, terbimbing, dan pemanfaatan sarana praktik/praktikum yang optimal sebagai satu kesatuan yang utuh dalam sistem penyelenggaraan praktikum, maka diharapkan dapat mencapai tujuan pembelajarannya dengan baik (Pertiwi, 2013).

\section{KESIMPULAN}

Berdasarkan hasil analisa data dan pembahasan maka dapat disimpulkan (1) Persepsi terhadap perencanaan praktikum Biologi Umum Jurusan Tadris Biologi IAIN Kerinci pertama, mengenai komunikasi antara dosen dan asisten masih kurang baik, kedua perlu tambahan asisten. Ketiga, dalam pembagian kelompok sudah baik dan merata. Keempat, alat dan bahan sebelum praktikum disiapkan oleh asisten dan sesuai dengan letaknya masing-masing. Kelima, pembagian alat praktikum sudah merata untuk semua kelompok. Keenam, informasi yang disampaikan asisten dosen ke praktikan sudah tersampaikan dengan baik. (2) Presepsi mahasiswa biologi semester 1 IAIN Kerinci mengenai sarana dan prasarana praktikum biologi umum dapat disimpulkan yaitu pertama: ada beberapa mikroskop yang rusak, mahasiswa praktikum sesuai dengan alat dan bahan yang adaa di labor, panduan praktikum masih belum lengkap dan belum memadai. (3) Presepsi mahasiswa biologi semester 1 IAIN Kerinci mengenai presepsi pelaksanaan praktikum boiologi umum, pertama pada setiap pelaksanaan praktikum, asisten dosen masih belum tepat menggunakann strategi dengan baik. Kedua, media yang ditampilkan sudah bagus. Ketiga, untuk jadwal praktikum sudah dikatakan sesuai jadwal.

\section{DAFTAR RUJUKAN}

Afifudin dan Beni Saebani 2012, Metodologi Penelitian Kualitatif. Yokyakarta: Arruz Media. 
Bafadal Ibrahim. 2003. Manajemen Perlengkapan Sekolah Teori dan Aplikasinya, Jakarta : Bumi Aksara.

Republik Indonesia Undang-undang tentang Pendidikan Nomor 12 tahun 2012.

Daryanto dan Rahardjo, M. 2012. Model Pembelajaran Inovatif. Yogyakarta: Gava Media.

Dewi Indah Sari, Sunariyati Siti dan Neneng Liswara. 2014. Analysis Of Constrains Biological Practicum Implementation In Senior High School As City As Palangka Raya, Jurnal Pendidikan Biologi dan Matematika Edu Sains Volume 2 Nomor 1, DOI: https://doi.org/10.23971/eds.v2i1.16.

Ferry, D. (2019). Peningkatan Hasil Belajar dan Keaktifan Mahasiswa Melalui Strategi Pembelajaran Peta Konsep Pada Mata Kuliah Evolusi. Journal on Education, 1(4), 809-816. Retrieved from http://www.jonedu.org/index.php/joe/article/view/249

Ferry, D., Jepriadi, \& Kamil, D. (2019). Peningkatan Hasil Belajar Biologi Siswa Melalui Penerapan Media Video Animasi Tiga Dimensi (3D). Pedagogi Hayati, 3(2), 1-11. doi:10.31629/ph.v3i2.1641

Gafur Nila Novita, Mohidin Abdul Djabar and Nurwan. 2013. Analisis Hasil Penelitian Kinerja Asisten Laboratorium Dengan Menggunakan Metode Analytical Hierarchy Process (AHP), Jurnal KIM Fakultas Matematika dan IPA, Vol. I, no. 1, Agustus 2013.

Hasruddin dan Rezeqi, S. 2012. Analisis Pelaksanaan Praktikum Biologi dan Permasalahannya di SMA Negeri SeKabupaten Karo. Jurnal Tabularasa PPS UNIMED 9(1): 17-32.

HIDAYAH, N. (2018). ANALISIS KESIAPAN MAHASISWA PRODI PENDIDIKAN GURU MADRASAH IBTIDAIYAH SEBAGAI CALON PENDIDIK PROFESIONAL. Terampil: Jurnal Pendidikan Dan Pembelajaran Dasar, 5(1), 116. doi:10.24042/terampil.v5i1.2936

Ida Malati Sadjati \& Pepi Rospina Pertiwi, 2013. Jurnal Pendidikan Terbuka dan Jarak Jauh, Volume 14, Nomor 1, Maret 2013, 45-56m, (Online) http://jurnal.ut.ac.id/ index.php/JPTJJ/article/view/128/103

Indrawan I. 2015. Pengantar Manajemen Sarana dan Prasarana Sekolah. Deepublish (Grup Penerbit CV Budi Utama):Yogyakarta.

Indriastuti, Herlina, L., dan Widiyaningrum, P. 2013. Kesiapan Laboratorium Biologi dalam Menunjang Kegiatan Praktikum SMA Negeri Di Kabupaten Brebes. Journal of Biology Education 2(2): 125-132.

Jayadiningrat Made Gautama, I Nyoman Tika, Ni Putu Yuliani. 2017. Meningkatkan Kesiapan dan Hasil Belaar Siswa pada Pembelajaran Kimia Dengan Pemberian Kuis di Awal Pembelajaran. Jurnal Pendidikan Kimia Indonesia. Volume 1, Nomor 1, 2017, DOI: http://dx.doi.org/10.23887/jpk.v1i1.12806.

Mastika I Nyoman, Adnyana I B Putu, Setiawan I Gusti N Agung. 2014. Analisis Standarisasi Laboratorium Biologi dalam Proses pembelajaran di SMA Negeri Kota Denpasar . Jurnal Pendidikan dan Pembelajaran IPA Indonesia, (Volume 4 Tahun 2014).

Megasari Rika .2014. Peningkatan Pengelolaan Sarana dan Prasarana Pendidikan Untuk Meningkatan Kualitas Pembelajaran Di SMPN 5 Bukittinggi, 
Volume 2 Nomor 1, Juni 2014 | Bahana Manajemen Pendidikan | Jurnal Administrasi Pendidikan Halaman 636 - 831. DOI : https://doi.org/10.23036/bmp.v2i1.3808.

Moleong, Lexy J. 2004, Metode Penelitian Kualitatif. Bandung: Rosda

Mulyono. 2009. Manajemen Administrasi dan Organisasi Pendidikan. Yogyakarta: Ar-Ruzz Media.

Pertiwi, R.I. 2013. Persepsi Mahasiswa tentang Penyelenggaraan Praktikum pada Pendidikan Tinggi Terbuka Jarak Jauh. Jurnal Pendidikan Terbuka dan Jarak Jauh 4 (1): 4556.

Rustaman N. 2010. Peranan praktikum dalam pembelajaran IPA (online) : Http://file.upi.edu/Direktori/SPS/Prodi Pendidikan IPA/195012311979032, diakses: 20 Mei 2019.

Sapuroh Siti. (2010). Analisis Kesulitan Belajar Siswa dalam Memahami Konsep Biologi pada Konsep Monera. Skripsi. Jakarta: UIN.

Saputro Budiono, 2016, Pengembangan Model Manajemen Pembelajaran Direct Intruction Berfokus Film Dalam Pengantar Praktikum IPA, e-Journal IAIN Syekh Nurjati Cirebo, ISSN: 2527-7588 e- Vol 1 January 2016.

Sastria Emayulia, Novinovrita, Maulana Arif, Novallyan Devie. 2018. Evaluasi Praktikum Botany Phanerogamae Dengan Menggunakan Model CSE-UCLA (Studi pada Mahasiswa Jurusan Tadris Biologi Institut Agama Islam Negeri Kerinci), Jurnal Biotek. Vol 6, No 2 (2018), ISSN Print: 2354-9106 ISSN Online: 2581-1827.

Sugiyono. 2013 Metode Penelitian Pendidikan. Bandung : Alfabeta.

Terry. 2000. Guide to Management, Diterjemahkan oleh J. Smith, Prinsip-prinsip Manajemen, cet. 6, Jakarta: PT. Bumi Aksara, h. 9. 